\title{
Size Adjectives and Adnominal Degree Modification
}

\author{
Marcin Morzycki \\ Michigan State University
}

\section{Introduction}

In languages that have them, adjectives and the functional structure they project are the prototypical means by which gradable notions are expressed, and consequently probably the clearest window available onto how degree modification works. But degree modification occurs outside the adjectival domain as well (a fact noted by Bolinger 1972, Abney 1987, Deut jes 1997, Kennedy and McNally 2004 among others), and the mechanisms that underlie gradability in these non-adjectival contexts remain largely mysterious. The big-picture aim of this paper is to shed some light onto one comer of this murky area by examining a variety of non-adjectival degree modification in which the gradable predicate is provided by a noun, and an adjective serves only to characterize the degree to which the gradable predicate holds. In the compositional semantics ultimately proposed here, core properties of this construction follow from a restriction on how degrees on one scale can be mapped to degrees on another and from a close structural parallel between the nominal and adjectival extended projections.

The phenomenon at issue here is exemplified in (1):

(1) a. George is an enormous idiot.

b. Gladys is a big beer-drinker.

c. Three huge goat-cheese enthusiasts were arguing in the comer.

d. Most really colossal curling fans are difficult to understand.

The most natural readings for the sentences in (1) don't involve any claim of large physical size; rather, the nominal predicate is claimed to hold to a high degree. Strikingly, these readings persist and are well-behaved in a variety of syntactic and semantic contexts, including comparatives, how-questions, and too-constructions:

(2) a. Gladys is a bigger idiot than Floyd.

b. How big an idiot is Gladys?

c. Gladys is too big an idiot to talk to.

The availability of such readings for size adjectives is not a peculiarity of English:

(3) SPANISH

Pedro es un gran idiota.

Pedro is a great idiot

'Pedro is a big idiot' 
(4)

POLISH

wielki idiota

great idiot

'big idiot'

Similar effects can be discerned in numerous other languages.

Section 2 examines this phenomenon in more detail, arguing that it not merely a reflection of some other linguistic (or extralinguistic) process. In doing so, two generalizations emerge: these readings are possible only in attributive (in English, prenominal) positions and, surprisingly, systematically only with adjectives that predicate bigness. In section 3, I propose an interpretation for these structures that accounts for these generalizations, considering two ways of doing this. The first builds on the intuition that nouns seem less context-sensitive than adjectives with respect to the standards that resolve vagueness; the second, on the notion that the polarity of a noun and a size adjective serving as its degree modifier must match. I settle on the latter. Section 4 develops a means of assembling this interpretation compositionally, advocating a structure for the extended NP that closely parallels that of the extended AP. Section 5 very briefly concludes.

\section{Two Generalizations and Some More Facts and Complications}

\subsection{The Position Generalization}

The degree reading of a size adjective seems to be unavailable in predicative positions-(5a) and (6a) are ambiguous, but (5b) and (6b) have only a literal-size reading: ${ }^{1}$

(5) a. that big beer-drinker

b. *That beer-drinker is big.

(6) a. George is an enormous idiot.

b. *George is an idiot, and he is enormous.

The degree reading is also impossible postnominally:

(7) a. a bigger beer-drinker than any I've met before

b. *a beer-drinker bigger than any I've met before

a. a $\left\{\begin{array}{l}\text { more enormous } \\ \text { bigger }\end{array}\right\}$ idiot than you can imagine

b. an idiot $\left\{\begin{array}{c}* \text { more enormous } \\ * \text { ?bigger }\end{array}\right\}$ than you can imagine

(9) a. too big a war-monger to tolerate

b. *a war-monger too big to tolerate 
This general pattern has analogues outside English. In Spanish and Polish, for example, degree readings are also impossible postnominally (as these languages can demonstrate perhaps more starkly than English can):

(10) SPANISH

a. Pedro es un gran idiota.

Pedro is a great idiot

'Pedro is hugely idiotic.'

b. Pedro es un idiota grande.

Pedro is a idiot great

'Pedro is physically large and an idiot.'

(11) POLISH
a. wielki kretyn
great cretin
'one who is hugely cretinous'
b. kretyn wielki
cretin great
'a cretin who is physically large'

And, like in English, these readings are impossible in predicative VP positions:

(12) SPANISH

Ese idiota es enorme.

This idiot is enormous

'The size of this idiot is large.'

(13) POLISH

Ten kretyn jest wielki

This cretin is great

'This cretin is large in size.'

This generalization can be stated more officially as in (14):

(14) The Position Generalization: Degree readings of size adjectives are possible only prenominally.

\subsection{The Bigness Generalization}

The other basic generalization in this domain is that adjectives that predicate bigness (that is, upward monotonic size adjectives) are systematically able to receive degree readings, but this is not the case for adjectives that predicate smallness: 
(15) George is a $\left\{\begin{array}{l}\text { enormous } \\ \text { huge } \\ \text { colossal } \\ \text { mammoth } \\ \text { gargantuan }\end{array}\right\}$ idiot.

(16) George is a $\left\{\begin{array}{l}*_{\text {tiny }} \\ *_{\text {minuscule }} \\ *_{\text {microscopic }} \\ *_{\text {diminutive }} \\ *_{\text {minute }}\end{array}\right\}$ idiot.

Adjectives of smallness may not be as systematic in resisting degree readings as adjectives of bigness are in accepting them. Slight, for example, has a degree reading as its most natural interpretation:

(17) George is a slight idiot.

This example is in several respects not clear-cut, though. For one thing, it is not at all clear that slight is a size adjective in the first place. It predicates, after all, something like slenderness, which is certainly related to size, but, equally certainly, not identical to it. Moreover, it's not clear that even this not-quite-size reading is retained in contemporary English as anything other than a literary affectation. And, to my knowledge, slight is the only possible adjective of smallness in English that has a degree reading, which suggests that this case really involves a distinct lexical meaning.

This contrasts sharply with adjectives that predicate bigness, which have a compatibility with degree readings that is not only systematic but actually seems to be productive. So far as I know, Godzilla-scale is not an existing English adjective of bigness, and Chihuahua-scale is not an existing adjective of smallness. With (18) and (19), I hereby attempt to coin them:
a. Holy crap, there's a Godzilla-scale chunk of rotting meat on your kitchen floor!
b. The bastard had a Godzilla-scale trust fund all his life.
a. I can almost make out somewhere in the distance the faintest glimmer of a Chihuahua-scale comet.
b. The model had this weird perky Chihuahua-scale nose.

While this sort of judgment is for obvious reasons not entirely straightforward, it seems natural to assign a degree interpretation to (20a), and distinctly more natural than assigning such a reading to (20b):

(20) a. He's a Godzilla-scale idiot.

b. He's a Chihuahua-scale idiot. 
If in fact a degree reading comes for free whenever a novel adjective of bigness is coined, it suggests strongly that the availability of degree readings is not an accidental lexical property of these adjectives, but rather an essential part of the job description for adjectives of bigness.

Like the Position Generalization, this pattem is not unique to English:

(21) SPANISH

Pedro es un pequeño idiota.

Pedro is a small idiot

'Pedro is both small and an idiot.'

(22) POLISH

mały kretyn

small cretin

'cretin small in size'

So, to state this generalization more officially:

(23) The Bigness Generalization: Adjectives that predicate bigness systematically license degree readings. Adjectives that predicate smallness don't generally license such readings.

\subsection{Not Just Vagueness, Not Just Metaphor}

A natural impulse at first glance is to regard degree readings of size adjectives as simply an instance of some broader cognitive process. Perhaps these readings arise as a kind of metaphor, one might suggest, or perhaps they are the product of a peculiar kind of vagueness. But the facts don't accord with such an understanding.

The contrast between the degree and size readings passes tests for distinguishing ambiguity from vagueness. If this were vagueness, it should be perfectly unremarkable to predicate big in (24) of a single conjoined NP with different readings for each conjunct. So too with enormous in (25). But in fact, doing so has the flavor of wordplay - the telltale sense of oddness characteristic of zeugma:

(24) a. The other driver was a really big bastard and basketball player.

b. The other driver was a really big basketball player and bastard.

(25) a. Larry is an enormous fan of curling and former mafia goon.

b. Larry is an enormous former mafia goon and fan of curling.

These examples are imperfect, however, in that it is possible in principle to alleviate the sense of oddness by construing the size adjective with the left conjunct alone. readings:

Perhaps a clearer result can be attained by explicitly blocking one of the

(26) a. Gladys isn't very big, but she is a very big beer-drinker.

b. Harry isn't enormous, but he is an enormous idiot. 
a. \#This chair isn't very big, but it is a very big chair.

b. \#That building isn't enormous, but it is an enormous building.

There is no sense of contradiction in (26), unlike in (27), because two distinct readings are involved, and one can be negated without negating the other.

Another, perhaps more promising approach along similar lines would be to construe degree readings of size adjectives as the outcome of an extra-linguistic cognitive process of metaphorical extension. But this raises numerous difficult questions that have much more straightforward answers if this is understood as a grammatical rather than extra-linguistic phenomenon. First, why should the availability of such metaphoric extension be sensitive to syntactic position? Second, why should this be possible only for adjectives of bigness? And third, why should these metaphors be apparently so conventionalized? That is, why should they come seemingly for free, with no conscious awareness by either speaker or hearer that something metaphoric has been said? These questions have natural answers if this is understood in grammatical rather than extralinguistic terms.

\subsection{Some Additional Distinctions}

There are at least two other uses of size adjectives that must be distinguished from true degree uses.

ABSTRACT SIZE READINGS Some ordinary size readings of size adjectives have a roughly degree-like flavor because of the nature of the modified NP:
a. an enormous mistake
b. a huge snowstorm
c. a big catastrophe
d. a huge problem

But these are not true degree readings. Rather, they are size readings that make reference to size along a possibly abstract dimension-one that may correlate with some intuitive sense of extremeness or severity. That is, these uses, unlike true degree readings, do seem to be in some important sense genuinely metaphorical. They pattern with ordinary size readings rather than with degree readings in several respects.

One of these is a systematic failure to accord with the Position Generalization-these readings can occur in predicative positions:

(29) a. That was a mistake, and it was enormous.

b. That was a snowstorm, and it was huge.

c. a catastrophe bigger than any other

d. a problem too huge to fully comprehend

Another is that they systematically fail to accord with the Bigness Generalizationadjectives that predicate smallness behave just like ones that predicate bigness: 
(30)

That was a $\left\{\begin{array}{l}\text { big } \\ \text { enormous } \\ \text { huge } \\ \text { colossal } \\ \text { mammoth } \\ \text { gargantuan }\end{array}\right\}$ mistake.

That was a $\left\{\begin{array}{l}\text { small } \\ \text { tiny } \\ \text { minuscule } \\ \text { microscopic } \\ \text { diminutive } \\ \text { minute }\end{array}\right\}$ mistake.

And finally, in these abstract-size cases, there is no ambiguity, no clear distinction between two readings, so sentences like (32) are contradictory:

(32) a. \#That mistake wasn't enormous, but it was a enormous mistake.

b. \#That snowstorm wasn't huge, but it was a huge snowstorm.

c. \#That catastrophe wasn't big, but it was a big catastrophe.

d. \#That problem wasn't huge, but it was a huge problem.

SIGNIFICANCE READINGS There is another, more puzzling use of size adjectives that has a non-size flavor. On this use, these adjectives seem to predicate (in)significance:

(33) a. the big political figures of the 20th century

b. a huge corporate mucky-muck

c. a small little man

d. some puny judge somewhere

I have no theory to offer of these readings, or even of what relation they might bear to abstract size readings. They are rather odd beasts. Unlike degree readings, significance readings don't involve degrees on a scale provided by the head noun (degrees of idiocy, of stamp-collector-hood, etc.). Rather, they always involve degrees of importance, irrespective of the noun. And unlike degree readings, significance readings don't accord with the Bigness Generalization. Adjectives of smallness give rise to these readings very naturally, as (33) reflects. Like degree readings, though, significance readings are sensitive to syntactic position. The nature of this sensitivity is unclear, though. They usually resist predicative uses, but in some cases allow them:
a. *? These political figures were big.
b. ${ }^{*}$ ?This corporate mucky-muck is huge.
c. ?This man is little. 


\section{The Interpretation, and Explaining the Bigness Generalization}

\subsection{An Initial Step: What Is Nominal Gradability?}

To begin developing an interpretation, it will be necessary to make some initial basic assumptions about how degrees and gradability work in the nominal domain. There are a number of possibilities. One natural course would be to adopt a supervaluation understanding of vagueness, in which there is no need for degrees as such in the first place (Kamp 1975, Fine 1975, others). Another would be to suppose that nouns-or at least certain nouns-have degree arguments and are associated with scales (a background assumption in e.g. Matushansky 2001). I adopt the second view here. Kennedy 1997 provides some arguments in favor of such degree-based explanations. But it is worth noting that the supervaluation approach might actually be particularly appropriate for nominals, because in the nominal domain linguistic manipulation of vagueness has a distinctly 'derived' or 'secondary' character that would seem to accord with this conception.

An important drawback of supposing that nouns may have degree arguments is that it levels the type-theoretic distinction between nouns and adjectives, thereby risking losing the generalization that it is adjectives, not nouns, that are the locus of gradability. But this could be avoided by simply assuming that degrees aren't arguments of nouns for compositional purposes, but are a kind of implicit argument that results in a pronoun-like dependence on a degree (much like e.g. the dependance of local on a contextually supplied place) $:^{2}$

$$
\llbracket \text { idiot }_{d} \rrbracket=\lambda \mathbf{x} . \mathrm{x} \text { is d-idiotic }
$$

This maintains the type-theoretic distinction between nouns and adjectives, but still provides access to the degree variable from higher up via binding.

\subsection{An Appealing But Flawed Approach: The Moderation Requirement}

Having made these assumptions, the task at hand is to provide a semantics that derives the Bigness Generalization-that is, a semantics for big idiot that explains what goes wrong in small idiot. I'll consider two options. The first of these seems to be fatally flawed, but I will sketch it here even so because it strikes me as having an intuitive appeal that perhaps the more empirically adequate alternative lacks.

The intuition behind this approach is that adjectives of smallness run afoul of a restriction on how contextually-supplied standards work in the nominal domain: standards associated with nouns cannot vary as freely as standards associated with adjectives. No matter how tall a basketball player is, if he is the shortest in the relevant comparison class, he will not count as tall. But it is certainly not the case that Isaac Newton would, given an appropriate comparison class, count as an idiot. This can be understood as a requirement that standards in the nominal domain must be neither set very high nor very low: 


\section{THE Moderation REQUIREMENT}

For any noun $\mathrm{N}$, the standard $\mathrm{s}_{[N]}$ the context fixes on the scale associated with $\mathrm{N}$ can't be a big degree and it can't be a small one:

$\neg \operatorname{big}\left(s_{[N]}\right) \wedge \neg \operatorname{small}\left(s_{[N]}\right)$

Of course, what counts as a big degree and what counts as a small one is itself context-sensitive. It is an important property of this approach that it involves predicating bigness and smallness directly of degrees. In most cases, predicating adjectival denotations of degrees would be bizarre-if degrees are simply intervals on a scale along some dimension, they aren't objects that can be surprising, for example, or lovely. But intervals do have size, so predicating bigness and smallness of them seems coherent.

To see how (37) helps, let's assume that the denotation of Floyd is a big idiot is as in (38), where $s_{\text {idiot }}$ is the contextually-supplied standard for idiocy:

$$
\begin{aligned}
& \text { 【Floyd is a big idiot 》 } \\
& =\exists \mathrm{d}: \neg \mathrm{big}\left(\mathrm{s}_{\text {idiot }}\right) \wedge \neg \operatorname{small}\left(\mathrm{s}_{\text {idiot }}\right) \text { [Floyd is d-idiotic } \wedge \mathrm{d} \geq \\
& s_{\text {idiot }} \wedge \operatorname{big}(d) \text { ] }
\end{aligned}
$$

This requires that for Floyd to be a big idiot, there must be a degree of his idiocy that both is big and exceeds (or meets) the standard. If big idiot leads to denotations like (38), it seems reasonable to suppose that small idiot would lead to denotations like (39):

$$
\begin{aligned}
& \llbracket \text { Floyd is a small idiot } \rrbracket \\
& =\exists \mathrm{d}: \neg \operatorname{big}\left(\mathrm{s}_{\llbracket \text { idiot } \rrbracket}\right) \wedge \neg \operatorname{small}\left(\mathrm{s}_{\llbracket \text { idiot } \rrbracket}\right)[\text { Floyd is d-idiotic } \wedge \mathrm{d} \geq \\
& \left.\quad \mathrm{s}_{\text {idiot }} \wedge \operatorname{small}(\mathrm{d})\right]
\end{aligned}
$$

This, though, necessarily results in failure of presupposition. Because of the monotonicity of small, if d-the degree of Floyd's height-is small and yet larger than the standard $s_{\text {idiot }}$, then $s_{\text {idiot }}$ must also be small. But this is precisely what the moderation requirement rules out. Of course, no such difficulty results for big idiot because $d$ can be both big and yet larger than the standard without requiring that the standard therefore also be big.

There is a significant problem with this approach, though. Because it relies on a constraint on standard-setting, it predicts that the Bigness Generalization should arise only where standards play a role in the semantics. ${ }^{3}$ One place where standards standardly don't come into play is in comparatives and superlatives. At least in English, though, the effect does not go away in these contextsinterestingly, though, the contrasts do seem a bit less clear:
a. Floyd is a $\left\{\begin{array}{c}\text { bigger } \\ \% \text { ? smaller }\end{array}\right\}$ idiot than Clyde is.
b. Floyd is the $\left\{\begin{array}{c}\text { biggest } \\ \% \text { ? smallest }\end{array}\right\}$ idiot I know. 
However intriguingly diminished the contrast seems to be, this is a profound problem for this kind of explanation. To be sure, one might imagine ways to navigate around it-none at all attractive-but unmistakably, this strikes at the very core of the idea.

\subsection{Another Approach: Relating Distinct Scales and Degree Polarity}

An alternative approach to explaining the Bigness Generalization takes as its starting point a different intuition about what goes wrong in small idiot: that the problem is one of adjectival polarity, in some ways comparable to what goes wrong in cross-polar anomaly (Kennedy 1997, 2001):

a. \#This book is longer than that one is short.

b. \#Floyd is taller than Clyde is short.

Kennedy advances a view of these facts in which adjective pairs of different polarity, such as big and small, involve degrees that are on the same scale (i.e., along the same dimension) but in principle incommensurable because of a fundamental sortal distinction between positive and negative degrees.

Building on Seuren 1978, 1984 and von Stechow 1984, he represents degrees as intervals ('extents'), with positive degrees extending from the lowermost portion of the scale to a positive point on the scale, and negative degrees extending from such a point upward to the uppermost portion of the scale. Thus if Floyd is 6 feet tall, the positive and negative degrees of his height will be as in (42):

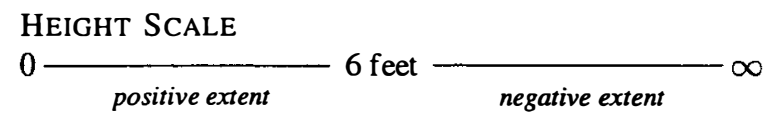

Antonymous adjectives involve the same scale, but different sorts of degrees-tall measures height in terms of positive degrees, and short in terms of negative ones. Given the right assumptions about how comparatives work, this explains cross-polar anomaly: For Floyd is taller than Clyde is short to be true, the degree to which Floyd is tall must properly include the degree to which Clyde is short. A degree of tallness is a positive degree; a degree of shortness a negative one. But because they are by definition complementary, a positive degree can't include a negative one. The sentence is therefore anomalous, because there can't in principle be a degree that satisfies it.

This may help with the problem at issue here. Perhaps idiot-and nouns generally - always involve positive degrees. ${ }^{4}$ On the assumptions above, it would already be the case that big involves positive degrees and small involves negative ones. Might the problem that underlies the Bigness Generalization, then, be that the negative degrees of small can't be compared in the right way with the positive degrees of $i d i o t$ ?

Expressing this idea in this Kennedy-style framework just as it is turns out to be awkward (though probably not impossible) because, fundamentally, these as- 
sumptions provide an account of incommensurability, but it's not at all clear that degrees of idiocy and degrees of bigness are in any real sense being compared to each other in the sense involved in cross-polar anomaly. A more congenial environment in which this line of thinking can be expressed may be available, though, in the general conception offered by a framework that makes an even more fundamental sortal distinction between positive and negative degrees. In Vector Space Semantics (Zwarts 1997, Zwarts and Winter 2000, Faller 2000, Winter 2001, Winter 2004): degrees are construed not as intervals but as vectors. They inherently encode direction on a scale, and are therefore inherently positive or negative (and not merely by virtue of which portion of a scale they occupy).

For current purposes, it will suffice to assume a bastardized toy version of the highly articulated conception of degrees as vectors developed by Faller 2000 and Winter 2004. I'll provide here only a thumbnail sketch of a few of the crucial features of this understanding of the ontology of degrees. First, scales themselves are defined as positive or negative. A scale is a pair of a basic 'unit vector' and a set of real numbers. Negative scales are just those with a negative unit vector. Second, there is a dimension function that maps an individual to a corresponding vector on some scale: $\operatorname{dim}_{S}(x)$ is the vector corresponding to $\mathrm{x}$ on the scale $\mathrm{S}$. Third, there is an anti-dimension function that maps a set of vectors onto a set of corresponding individuals: $\operatorname{dim}_{\overline{\mathrm{S}}}(\mathrm{v})$ is the set of individuals such that the dimension function maps them to $\mathrm{v}$ on $\mathrm{S}^{5}$

Very roughly, the denotation of a simple unmodified adjective such as tall is along the lines of (43) (where the polarity of the scale is explicitly indicated with + or - ):

$$
\llbracket \text { Mary is tall } \rrbracket=\operatorname{dim}_{+ \text {height }}(\text { Mary })>s_{+ \text {height }}
$$

That is, Mary is tall asserts that Mary's vector on the scale of positive height-that is, the scale of tallness - exceeds the contextually-supplied standard vector for that scale.

Maybe, then, big idiot can be interpreted as involving a kind of double mapping - first an individual is mapped onto a corresponding vector on the scale of idiocy, then that vector itself is mapped onto a corresponding vector on the scale of bigness. This is, of course, simply the reflection in this framework of the idea that degree readings of size adjectives involve predicating size adjectives directly of degrees. Thus big idiot will be interpreted as in (44a), and, analogously, small idiot as in (44b):

$$
\begin{gathered}
\text { a. } \llbracket \text { big idiot } \rrbracket=\lambda \mathbf{x} \cdot \operatorname{dim}_{+ \text {idiocy }}(\mathbf{x})>\mathrm{s}_{+ \text {idiocy }} \wedge \\
\operatorname{dim}+\text { size }\left(\operatorname{dim}_{+ \text {idiocy }}(\mathbf{x})\right)>\mathrm{s}_{+ \text {size }} \\
\text { b. } \llbracket \text { small idiot } \rrbracket=\lambda \mathbf{x} \cdot \operatorname{dim}_{+ \text {idiocy }}(\mathbf{x})>\mathrm{s}_{+ \text {idiocy }} \wedge \\
\operatorname{dim}_{- \text {size }}\left(\operatorname{dim}_{+ \text {idiocy }}(\mathbf{x})\right)>\mathrm{s}_{- \text {size }}
\end{gathered}
$$

Perhaps what goes awry in small idiot, then, is the mapping from an idiocy degree to a size degree. In (44b), the dimension function is serving as a kind of polarityreverser, mapping a positive degree onto a negative one. There is probably no reason 
why this should be impossible a priori. But likewise, it seems reasonable to suppose that the grammar might rule out this kind of operation, either in general or (more plausibly) in particular constructions.

The idea, then, is that it may be simply a fact about how degrees on one scale are mapped onto another - or at least about how the size of degrees is evaluated, at least in this construction - that polarity is always preserved. Phrasing it metaphorically, the size of degrees is always evaluated by measuring in the direction of the vector, along the grain, so to speak. More precisely:

Polarity PREservation PRINCIPLE

For any scale $S$ and degree $d$ of the same polarity, $\operatorname{dim}_{+s}(-d)$ and $\operatorname{dim}_{-s}(+d)$ are both undefined.

It would of course be a more interesting result to find evidence of this at work more generally in the grammar. Certainly, framed as it is here, it has the character of something one might expect to be more general. But by the same token, if the Moderation Requirement could be understood as simply a presupposition arising from how the nominal extended projection is organized, it seems reasonable that this might be understood in these terms as well.

\section{Assembling the Interpretation Syntactically}

\subsection{Degree Head In NP?}

To assemble the denotations above, something must introduce the semantic glue that relates the adjective and the noun in the appropriate way. There is reason to think that the syntax provides just such a thing-namely, a degree head in the nominal extended projection:

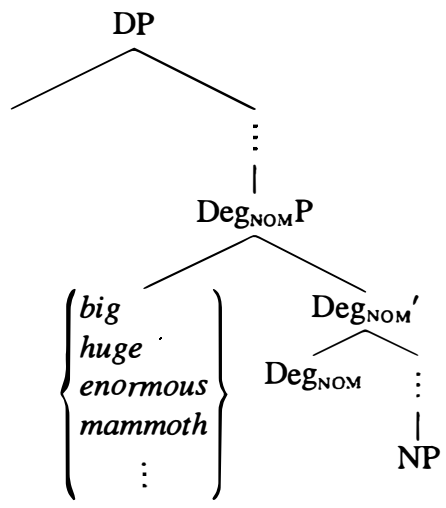

As (46) reflects, a particular Deg $_{\text {NOM }}$ head may introduce size adjectives with degree readings in its specifier. 


\subsection{Relieving Functional Head Nausea}

If degree readings of size adjectives were the only motivation for a nominal degree head, this might be unappealing. But in fact, there is a battery of independent arguments for such a thing:

ARGUMENT 1: One is a purely theoretical argument: there is something virtually inevitable about a nominal degree argument if we adopt the Abney 1987 proposal that As can be heads in the nominal projection along with the common view that the extended AP is headed by a Deg projection (Corver 1990, Kennedy 1997, others).

ARGUMENT 2: A related argument: the semantics Kennedy assigns to adjectives essentially requires a Deg head to occur immediately above every AP. For Kennedy, an AP denotes a measure function that yields degrees. A DegP, on the other hand, is a predicate of individuals. Kennedy proposes that the role of Deg is to map from the former type to the latter. So, if As can occur in the extended nominal projection as Abney suggests, Degs must on this view occur above them in order to provide a predicate of individuals for a $\mathrm{D}$ to ultimately combine with.

ARGUMENT 3: There are many expressions that plausibly spell out such a Deg head. Most of these appear superficially to be adjectives:

$$
\text { a }\left\{\begin{array}{l}
\text { real } \\
\text { true } \\
\text { total } \\
\text { complete }
\end{array}\right\} \text { idiot }
$$

But these are not adjectival uses of these expressions. The adjectival homophones of all these expressions can occur predicatively, but these nominal degree words can only occur attributively:

$$
\text { *That idiot is }\left\{\begin{array}{l}
\text { real } \\
\text { true } \\
\text { total } \\
\text { complete }
\end{array}\right\} \text {. }
$$

On the degree reading, these are all impossible - they have only the ordinary nondegree reading in this position.

ARGUMENT 4: Treating such uses of real and others as nominal Deg heads accounts for their inability to occur with their own degree words, as their adjectival counterparts can:
a. *a very real $\left\{\begin{array}{l}\text { problem } \\ \text { idiot }\end{array}\right\}$
b. *several quite true $\left\{\begin{array}{l}\text { observations } \\ \text { idiots }\end{array}\right\}$ 
c. *a fairly complete $\left\{\begin{array}{l}\text { description } \\ \text { idiot }\end{array}\right\}$

Again, in all these cases, only the normal adjectival non-degree reading is possible. (Similar superficially adjective-like adnominal degree words can be detected in other languages as well.)

ARGUMENT 5: The expressions that are plausible nominal degree words are of exactly the sort that historically develop into Deg heads in the adjectival domainthat is, they are cognate with the same kind of adjective. Adjectival Deg heads arise from expressions meaning roughly 'real' or 'true' as in (50), and the examples in (51) are even more transparent: ${ }^{6}$ :

a. verily $\rightarrow$ very

b. real $\rightarrow$ real (in e.g. real tall)

a. complete $\rightarrow$ completely

b. total $\rightarrow$ totally

ARGUMENT 6: Placing size adjectives in the specifier of a nominal functional projection accords with a well-established line of research that associates adjectives with specifier positions of nominal functional heads (Cinque 1994, Laenzlinger 2000 and many others).

ARGUMENT 7: This sort of structure provides a natural parse for more of $a$ structures like (52):

(52) He met [DP [DegP more [PP of an idiot]]] the day after.

ARGUMENT 8: Measure phrases inside DP such as those in (53) might also benefit from this sort of analysis:

a. a five-mile hike

b. a two-pound bag

If these measure phrases were placed in the specifier position of nominal DegP, this would parallel the structure of measure phrases in AP (Abney 1987, Corver 1990, Kennedy 1997, Grimshaw 1991), and perhaps in PP and VP (Morzycki 2004) as well.

ARGUMENT 9: A not quite independent argument: I have not relied on restrictions on what adjectives can co-occur with size adjectives that receive degree readings, but they seem to support a similar conclusion. It is not in general possible for other adjectives to occur above these size adjectives:
a. *? a dangerous big idiot
b. *? some happy enormous fans of curling
c. $*$ ? the popular gargantuan stars of the ' 40 s 
If nominal DegP occupies a fixed position high in DP, above where most adjectives adjoin, this alone would rule out such sentences.

The Position Generalization: Perhaps the most important argument, though, is the Position Generalization itself. If size adjectives receive degree readings only in the specifier of a nominal degree projection as proposed here, it follows that they can only be used attributively.

\subsection{How Things Fit Together}

This kind of structure provides a natural way to build up the denotations proposed earlier, on either of the approaches to the semantics considered above. Since it better accords with the data, I will adopt the vector-space(-flavored) approach to illustrate this here.

For the size adjective itself - or rather its extended projection-it suffices to assume that it denotes a simple property of individuals (where $s_{+ \text {size }}$ is the standard for positive size, that is, for bigness): ${ }^{7}$

$$
\llbracket \operatorname{big}_{s_{+s i z e}} \rrbracket=\lambda \mathbf{x} \cdot \operatorname{dim}_{+ \text {size }}(\mathbf{x})>s_{+ \text {size }}
$$

With appropriate modifications, the previously suggested denotation for idiot could remain essentially intact:

$$
\llbracket \text { idiot }_{d, s_{\text {+idiocy }}} \rrbracket=\lambda \mathbf{x} \cdot \operatorname{dim}_{+ \text {idiocy }}(\mathbf{x})=\mathrm{d} \wedge \mathrm{d}>\mathrm{s}_{\text {+idiocy }}
$$

In the spirit of Kennedy 1997, I assume here that the nominal degree head does the compositional heavy-lifting of relating the size adjective and the noun by 'finding' the degree variable (by binding it) and offering it up for modification: ${ }^{8}$

$$
\llbracket \mathrm{DEG}-\mathrm{SIZE} \rrbracket=\lambda \mathrm{N}_{\langle d,\langle e, t\rangle\rangle} \lambda \mathrm{A}_{\langle e, t\rangle} \lambda \mathrm{x} \cdot \mathrm{A}(\iota \mathrm{d}[\mathrm{N}(\mathrm{d})(\mathrm{x})])
$$

If it tums out to be necessary, as seems likely though less interesting, to associate the Polarity Preservation Principle of section 3 with this construction specifically, the denotation of DEG-SIZE would of course be the natural place to locate this restriction.

The denotation in (57) applies to functions from degrees to noun denotations. If a noun has an implicit degree variable as in (56), DEG-SIZE can bind this degree variable. The outcome:

$$
\begin{aligned}
& \text { a. 【DEG-SIZE }{ }_{d} \text { idiot }_{d, s_{\text {+idiocy }}} \rrbracket \\
& =\llbracket \text { DEG-SIZE } \rrbracket\left(\llbracket \text { idiot }_{d, s_{\text {+idion }}} \rrbracket\right) \\
& =\lambda \mathrm{A}_{\langle e, t\rangle} \lambda \mathrm{x} \cdot \mathrm{A}\left(\iota \mathrm{d}\left[\operatorname{dim}_{+ \text {idiocy }}(\mathrm{x})=\mathrm{d} \wedge \mathrm{d}>s_{+ \text {idiocy }}\right]\right) \\
& \text { b. 【big DEG-SIZE } \text { idiot }_{d, s_{+i d i o c y}} \rrbracket \\
& =\llbracket \mathrm{DEG} \mathrm{SIZE}_{d} \text { idiot }_{d, s_{\text {+idiocy }}} \rrbracket(\llbracket \text { big } \rrbracket) \\
& =\operatorname{dim}_{+ \text {size }}\left(\iota \mathrm{d}\left[\operatorname{dim}_{+ \text {idiocy }}(\mathrm{x})=\mathrm{d} \wedge \mathrm{d}>s_{+ \text {idiocy }}\right]\right)>s_{+ \text {size }}
\end{aligned}
$$

This seems to yield the right truth conditions. 


\section{A Final Word}

To summarize, a core empirical argument here has been that degree readings of size adjectives are a distinct linguistic phenomenon, and not merely a consequence of vagueness or metaphor. Further, these readings are systematically possible only with adjectives of bigness, a fact ultimately explained here by supposing that the polarity of a noun and a size adjective serving as its degree modifier must match. The alternative possibility was also considered that this might be explained instead by supposing that nominal vagueness tolerates only moderate values for contextuallysupplied standards. The proposed interpretation relies on a nominal Degree head, and a range of independent evidence for the existence of such a projection was provided.

There are, of course, many unanswered questions in this general domain, but there are a few of particularly direct relevance that have not been addressed here. Among them is the question of what the semantics is of the other nominal degree heads proposed here, and of what might be revealed about the cross-categorial nature of degree modification by a comparative examination of these degree heads and the familiar ones in the extended AP. Also unaddressed here is the question of how nominal scale structure can vary. For example, does the contrast between complete idiot and *complete smoker indicate that idiocy has an upper bound and smoker-hood does not? And this area too provides a place where the nominal and adjectival degree systems might fruitfully be compared, perhaps shedding some light on gradability more generally. There is also a much more local but nonetheless vexing question on which I can currently say nothing: Why does large idiot seem so odd? A degree reading is not very natural here, but, given what has been said here, it is not altogether obvious precisely what it is about large that renders it something other than a size adjective in the appropriate sense. This would be more alarming if it weren't the case that large and big do seem to contrast in some very distinct though highly elusive way. But even so, some additional clarity on this point would be welcome. Finally, there are cross-linguistic questions to be asked. The construction examined here recurs in many languages, and indeed is not limited even to Indo-European (Hebrew has an analogue, for example). This in itself may require some explanation. In examining these cross-linguistic facts, though, interesting points of variation emerge that warrant further scrutiny and may significantly alter the broader picture.

\section{Endnotes}

*Thanks to Alan Bale, Ana Arregui, Angelika Kratzer, Anna Maria di Sciullo, Anne-Michelle Tessier, Artemis Alexiadou, Bernhard Schwarz, Britta Sauereisen, Calixto Aguero-Bautista, Chris Barker, Chris Kennedy, Iannis Thomadakis, Jan Anderssen, Jonny Butler, Rajesh Bhatt, and audiences at SALT and the University of Stuttgart. This work was supported by the Social Sciences and Humanities Research Council of Canada (grant number 412-2003-1003 to Anna Maria di Sciullo 
and the Interface Asymmetries Project at the Université du Québec à Montréal). ${ }^{1}$ I will use a star to indicate ungrammaticality on the degree reading.

${ }^{2}$ Strictly speaking, this won't yet do-it doesn't seem to have the consequence that only idiots be in the extension of idiot-so it actually has to involve two implicit degree arguments, one of them the contextually-supplied standard normally assumed for adjectives as well.

${ }^{3}$ Thanks to Bernhard Schwarz and Rajesh Bhatt to bringing this problem into sharper focus for me.

${ }^{4}$ This is not an obvious or trivial assumption-if $d u m b$ involves negative degrees, as it probably does, idiot might seem to as well. On the other hand, negative degrees are really just ways of talking about the marked members of pairs that express opposite polarities; it makes sense to think of short as involving negative degrees because it is the marked member of the pair $\langle s h o r t, t a l l\rangle$. Nouns, on the other hand, don't normally come in pairs of opposite polarity (modulo cases such as (??shortness, height $\rangle$ ) - there is no unmarked noun that expresses the opposite of idiot.

${ }^{5}$ One important respect in which I'm simplifying dramatically here is that all the vectors mentioned so far are 'located vectors', which are understood as a pair of vectors. The first member of this pair is, in the cases relevant here, a trivial zero vector.

${ }^{6}$ The arrows here informally represent historical development.

${ }^{7}$ Importantly, since both degrees and ordinary individuals can have bigness predicated of them, $x$ here has to be construed to range over both; that is, I assume that the domain of degrees $D_{d}$ is a proper subset of $D_{e}$. (It would probably convenient, then, to distinguish a type for ordinary individuals, but for the sake of notational familiarity I won't do that here.

${ }^{8}$ We might also assume, to better parallel the semantics of degree words in the adjectival system and in particular the semantics Kennedy proposes for the adjectival degree head counterpart of DEG-SIZE, that it introduces the standard and relates it to the nominal denotations. But placing reference to the standard here, rather than inside the denotation of the noun, would risk losing the generalization that gradable nominals always involve exceeding their standard, even in comparative contexts (Floyd is a bigger idiot than Clyde). Of course, no harm would be done by supposing that DEG-SIZE introduces this information redundantly.

\section{References}

Abney, Steven: 1987, The English Noun Phrase in Its Sentential Aspect, PhD thesis, MIT, Cambridge, Massachusetts.

Bolinger, Dwight: 1972, Degree Words, Mouton, The Hague.

Cinque, Guglielmo: 1994, 'Evidence for partial N-movement in the Romance DP', In Cinque, G. et al. (eds), Paths Toward Universal Grammar: Essays in Honor of Richard S. Kayne. Georgetown University Press, Washington.

Corver, Norbert: 1990, The Syntax of Left Branch Extractions, PhD thesis, Tilburg 
University.

Deutjes, Jenny: 1997, Quantfiers and Selection, PhD thesis, Rijksuniversiteit Leiden.

Faller, Martina: 2000, 'Dimensional Adjectives and Measure Phrases in Vector Space Semantics', In M. Faller, S. Kaufmann, and M. Pauly, (eds), Formalizing the Dynamics of Information, CSLI Publications, Stanford.

Fine, Kit: 1975, 'Vagueness, Truth, and Logic', Synthese, 30:265-300.

Grimshaw, Jane: 1991, 'Extended projection', In Lexical Specification and Lexical Insertion, Erlbaum, Hillsdale, $\mathrm{NJ}$.

Kamp, Hans: 1975, 'Two Theories About Adjectives', In E.L. Keenan, (eds), Formal Semantics of Natural Language, pages 123-155, Cambridge University Press, Cambridge, England, 1975.

Kennedy, Christopher: 1997, Projecting the Adjective: The Syntax and Semantics of Gradability and Comparison, $\mathrm{PhD}$ thesis, University of California, Santa Cruz, Published in 1999 by Garland, New York.

Kennedy, Christopher: 2001, 'Polar Opposition and the Ontology of 'Degrees' ', Linguistics and Philosophy, 24:33-70.

Kennedy, Christopher and Louise McNally: 2004, 'Scale Structure and the Semantic Typology of Gradable Predicates', Under review for Language.

Laenzlinger, Christopher: 2000, 'French Adjective Ordering: Perspectives on DPInternal Movement Types', In Generative Grammar in Geneva, volume 1, pages 55-104, 2000.

Matushansky, Ora: 2001, 'Obligatory Scalarity (A Sliding Scale)', In K. Megerdoomian and L.A. Bar-el, (eds), Proceedings of the West Coast Conference on Formal Linguistics (WCCFL) XX, Somerville, Mass, Cascadilla Publications.

Morzycki, Marcin: 2004, 'Measure DP adverbials: Measure Phrase Modification in VP', Ms., Université du Québec à Montréal.

Seuren, Pieter: 1984, 'The Comparative Revisited', Journal of Semantics, 3:109141.

Seuren, Pieter: 1978, 'The Structure and Selection of Positive and Negative Gradable Adjectives', In Papers from the Parasession on the Lexicon, Chicago Linguistics Society.

von Stechow, Amim: 1984, 'My Reply to Cresswell's, Hellan's, Hoeksema's and Seuren's Comments', Journal of Semantics, 3:183-199.

Winter, Yoad: 2001, 'Measure Phrase Modification in Vector Space Semantics', In K. Megerdoomian and L.A. Bar-el, (eds), Proceedings of WCCFL XX, Somerville, Massachusetts, Cascadilla Publications.

Winter, Yoad: 2004, 'Cross-categorial Restrictions on Measure Phrase Modification', Ms, Technion-Israel Institute of Technology.

Zwarts, Joost: 1997, 'Vectors As Relative Positions: A Compositional Semantics of Modified PPs', Journal of Semantics, 14:57-86.

Zwarts, Joost and Yoad Winter: 2000, 'Vector Space Semantics: A Modeltheoretic Analysis of Locative Prepositions', Journal of Logic, Language and Information, 9:171-213. 